\title{
The impact of age and performance status on the efficacy of osimertinib in patients with EGFR T790M-positive non-small cell lung cancer
}

\author{
Hyun-Il Gil, Sang-Won Um \\ Division of Pulmonary and Critical Care Medicine, Department of Medicine, Samsung Medical Center, Sungkyunkwan University School of \\ Medicine, Seoul, Korea \\ Correspondence to: Sang-Won Um, MD, MPH, PhD. Division of Pulmonary and Critical Care Medicine, Department of Medicine, Samsung Medical \\ Center, Sungkyunkwan University School of Medicine, 81 Irwon-ro, Gangnam-gu, Seoul 06351, Korea. Email: sangwonum@skku.edu. \\ Provenance and Peer Review: This article was commissioned by the Editorial Office, fournal of Thoracic Disease. The article did not undergo external \\ peer review. \\ Comment on: Kato Y, Hosomi Y, Watanabe K, et al. Impact of clinical features on the efficacy of osimertinib therapy in patients with T790M-positive \\ non-small cell lung cancer and acquired resistance to epidermal growth factor receptor tyrosine kinase inhibitors. J Thorac Dis 2019;11:2350-60.
}

Submitted Nov 29, 2019. Accepted for publication Dec 13, 2019.

doi: $10.21037 /$ jtd.2019.12.80

View this article at: http://dx.doi.org/10.21037/jtd.2019.12.80

The last decade has seen remarkable advances in the treatment of non-small cell lung cancer (NSCLC), especially targeted therapy. Since the efficacy of gefitinib [the first-generation epidermal growth factor receptor (EGFR)-tyrosine kinase inhibitor (TKI)] for patients with advanced lung adenocarcinoma was proven 10 years ago (1), many recent works have shown that EGFR-TKIs exhibit better treatment efficacies than platinum-based chemotherapy in patients with NSCLCs harboring EGFR mutations (2-4). However, although 1st or 2nd-generation EGFR-TKIs such as erlotinib, gefitinib, or afatinib are superior to conventional chemotherapy, disease progression and EGFR-TKI-resistance usually develop within 1-2 years of treatment (1-4).

Osimertinib is a $3 \mathrm{rd}$-generation EGFR-TKI that irreversibly inhibits both EGFR-TKI sensitizing mutations and Thr790Met (T790M) mutation but exhibits less activity against the wild-type protein (5). The AURA trial series showed that osimertinib was remarkably effective in patients with NSCLC patients with acquired EGFR T790M mutations which developed after previous treatment of 1 st or 2nd-generation of EGFR-TKIs (6). AURA 3 study revealed that the median progression-free survival (mPFS) of patients given osimertinib was significantly longer than that of patients given platinum plus pemetrexed (10.1 vs. 4.4 months) (7). The objective response rate (ORR) was also significantly higher in the former patients
(71\% vs. 31\%). Even in patients with central nervous system (CNS) metastases, osimertinib afforded a longer mPFS than did platinum plus pemetrexed (8.5 vs. 4.2 months) (7). Osimertinib is less active toward wild-type than mutant EGFR (8), but the drug also exhibits higher-level CNS penetration and activity than do previous-generation EGFR-TKIs $(9,10)$.

In the FLAURA study, osimertinib was more efficacious than $1^{\text {st }}$ or $2^{\text {nd }}$-generation EGFR-TKIs when used as firstline treatment for the patients with advanced NSCLC who were positive for EGFR mutation. The mPFS afforded by first-line osimertinib was significantly longer than that associated with first-line 1st-generation EGFR-TKIs (18.9 vs. 10.2 months) (11). Osimertinib not only prolonged the mPFS but also overall survival (OS). In a very recent report on OS in the FLAURA, patients who received firstline osimertinib exhibited a longer median OS than did those who received 1st-generation EGFR-TKIs (38.6 vs. 31.8 months) (12). The safety profile of osimertinib was similar to those of other EGFR-TKIs $(11,12)$.

As human life expectancy increases, the average age of lung cancer patients also increases. The incidence of lung cancer increases with age, being highest among those aged $\geq 75$ years $(13,14)$. Therefore, physicians are encountering increasing numbers of older NSCLC patients of poor performance status. Kato et al. explored how clinical characteristics affected the efficacy of osimertinib 
therapy in patients with NSCLC harboring T790M EGFR mutation and acquired resistance to prior EGFR-TKIs (15). The study enrolled 31 patients of whom eight were categorized as younger patients ( $<65$ years) and 23 were categorized as older patients ( $\geq 65$ years). Other clinical characteristics (sex, smoking history, previous therapies, type of EGFR mutation, and CNS metastasis status) did not differ significantly between the groups. The PFS was significantly shorter in younger patients in comparison with older patients ( 3.5 vs. 6.4 months, $\mathrm{P}=0.041$ ) and the OS tended to be shorter in younger patients in comparison with older patients (5.3 vs. 19.4 months, $\mathrm{P}=0.067)$. The PFS (9.1 vs. 5.5 months; $\mathrm{P}=0.071$; HR, 0.38) was shorter in patients with poor Eastern Co-operative Oncology Group performance status (ECOG-PS) in comparison with those with good ECOS-PS. On multivariable analysis, ECOG-PS and age remained as independent predictors of the efficacy of osimertinib. The authors concluded that younger age and poor performance status were associated with the lower efficacy of osimertinib in patients with T790M-positive NSCLC. The association between poor performance status and lower efficacy is understandable. However, the association between younger age and poor performance status is debatable. In previous studies, older patients exhibited higher EGFR-TKI response rates and longer OS $(16,17)$. Wu et al. found that age $\leq 50$ years was associated with a poor response to EGFR-TKI. However, in the analysis of BR.21 trial, age did not significantly affect the response rate, PFS, or OS associated with erlotinib treatment (18). The inconsistencies may be attributable to differences in study design, the small sample sizes, and the use of different EGFR-TKIs and definitions of young age.

Previous studies showed that none of age, body weight, gender, or ethnicity exerted a clinically relevant effect on pharmacological clearance/exposure of $1^{\text {st }}$ or $2^{\text {nd }}$-generation EGFR-TKIs (19-21). A pharmacokinetic study of osimertinib found that none of age, sex, or smoking status affected the pharmacokinetics (22). However, age would affect the response to EGFR-TKIs. Older patients are more likely than younger patients to have comorbidities and, thus, to take other drugs. Concurrent medications may affect the pharmacokinetics of EGFR-TKIs (21), elevating the plasma level of osimertinib. Notably, the cited work found more adverse events in older patients, perhaps associated with the higher plasma level of osimertinib (15). The work did not discuss comorbidities, concurrent medications, or plasma osimertinib levels. Another study is needed to explore associations between age, concurrent medications, osimertinib plasma concentration, and the osimertinib response.

In addition, younger patients may have fewer uncommon EGFR mutations than older patients (23). Uncommon EGFR mutations include mutations other than the exon $19 \mathrm{del}$ and L858R mutations. One retrospective study found that young, Asian NSCLC patients had fewer EGFR mutations, but the types thereof were more uncommon (23). Two uncommon or compound mutations were detected only in older patients (thus, in no young patients); the presence of uncommon mutations, therefore, did not explain the poor response to osimertinib among young patients of the cited work (15). However, it is possible that other genetic changes might exist in young patients more commonly than in older patients, and that these might compromise the efficacy of EGFR-TKIs. A recent study found that the molecular features of lung adenocarcinomas in patients aged $\leq 35$ years differed from those of older patients (24).

Although the cited authors addressed the impact of age on the response to osimertinib in patients with EGFR T790M-positive NSCLCs, it may be too early to conclude that younger age predicts poor osimertinib efficacy. Further in-depth genetic analysis and measurement of osimertinib plasma concentrations are needed.

\section{Acknowledgments}

Funding: This work was supported by the National Research Foundation of Korea (NRF) grant funded by the Korea government (MSIT) (2019R1A4A1028268).

\section{Footnote}

Conflicts of Interest: The authors have no conflicts of interest to declare.

Ethical Statement: The authors are accountable for all aspects of the work in ensuring that questions related to the accuracy or integrity of any part of the work are appropriately investigated and resolved.

Open Access Statement: This is an Open Access article distributed in accordance with the Creative Commons Attribution-NonCommercial-NoDerivs 4.0 International License (CC BY-NC-ND 4.0), which permits the noncommercial replication and distribution of the article with the strict proviso that no changes or edits are made and the original work is properly cited (including links to both the formal publication through the relevant DOI and the license). See: https://creativecommons.org/licenses/by-nc-nd/4.0/. 


\section{References}

1. Mok TS, Wu YL, Thongprasert S, et al. Gefitinib or carboplatin-paclitaxel in pulmonary adenocarcinoma. N Engl J Med 2009;361:947-57.

2. Janne PA, Wang X, Socinski MA, et al. Randomized phase II trial of erlotinib alone or with carboplatin and paclitaxel in patients who were never or light former smokers with advanced lung adenocarcinoma: CALGB 30406 trial. J Clin Oncol 2012;30:2063-9.

3. Maemondo M, Inoue A, Kobayashi K, et al. Gefitinib or chemotherapy for non-small-cell lung cancer with mutated EGFR. N Engl J Med 2010;362:2380-8.

4. Rosell R, Carcereny E, Gervais R, et al. Erlotinib versus standard chemotherapy as first-line treatment for European patients with advanced EGFR mutation-positive non-smallcell lung cancer (EURTAC): a multicentre, open-label, randomised phase 3 trial. Lancet Oncol 2012;13:239-46.

5. Cross DA, Ashton SE, Ghiorghiu S, et al. AZD9291, an irreversible EGFR TKI, overcomes T790M-mediated resistance to EGFR inhibitors in lung cancer. Cancer Discov 2014;4:1046-61.

6. Janne PA, Yang JC, Kim DW, et al. AZD9291 in EGFR inhibitor-resistant non-small-cell lung cancer. N Engl J Med 2015;372:1689-99.

7. Mok TS, Wu YL, Ahn MJ, et al. Osimertinib or PlatinumPemetrexed in EGFR T790M-Positive Lung Cancer. N Engl J Med 2017;376:629-40.

8. Jiang T, Zhou C. Clinical activity of the mutant-selective EGFR inhibitor AZD9291 in patients with EGFR inhibitor-resistant non-small cell lung cancer. Transl Lung Cancer Res 2014;3:370-2.

9. Ballard P, Yates JW, Yang Z, et al. Preclinical Comparison of Osimertinib with Other EGFR-TKIs in EGFR-Mutant NSCLC Brain Metastases Models, and Early Evidence of Clinical Brain Metastases Activity. Clin Cancer Res 2016;22:5130-40.

10. Zhong WZ, Zhou Q, Wu YL. The resistance mechanisms and treatment strategies for EGFR-mutant advanced nonsmall-cell lung cancer. Oncotarget 2017;8:71358-70.

11. Soria JC, Ohe Y, Vansteenkiste J, et al. Osimertinib in Untreated EGFR-Mutated Advanced Non-Small-Cell Lung Cancer. N Engl J Med 2018;378:113-25.

12. Ramalingam SS, Vansteenkiste J, Planchard D, et al. Overall Survival with Osimertinib in Untreated, EGFR-Mutated Advanced NSCLC. N Engl J Med 2020;382:41-50.

13. Gajra A, Akbar SA, Din NU. Management of Lung Cancer in the Elderly. Clin Geriatr Med 2016;32:81-95.

14. Henley SJ, Richards TB, Underwood JM, et al. Lung cancer incidence trends among men and women--United States,
2005-2009. MMWR Morb Mortal Wkly Rep 2014;63:1-5.

15. Kato Y, Hosomi Y, Watanabe K, et al. Impact of clinical features on the efficacy of osimertinib therapy in patients with T790M-positive non-small cell lung cancer and acquired resistance to epidermal growth factor receptor tyrosine kinase inhibitors. J Thorac Dis 2019;11:2350-60.

16. Thatcher N, Chang A, Parikh P, et al. Gefitinib plus best supportive care in previously treated patients with refractory advanced non-small-cell lung cancer: results from a randomised, placebo-controlled, multicentre study (Iressa Survival Evaluation in Lung Cancer). Lancet 2005;366:1527-37.

17. Spigel DR, Lin M, O'Neill V, et al. Final survival and safety results from a multicenter, open-label, phase $3 \mathrm{~b}$ trial of erlotinib in patients with advanced nonsmall cell lung cancer. Cancer 2008;112:2749-55.

18. Wheatley-Price P, Ding K, Seymour L, et al. Erlotinib for advanced non-small-cell lung cancer in the elderly: an analysis of the National Cancer Institute of Canada Clinical Trials Group Study BR.21. J Clin Oncol 2008;26:2350-7.

19. Freiwald M, Schmid U, Fleury A, et al. Population pharmacokinetics of afatinib, an irreversible ErbB family blocker, in patients with various solid tumors. Cancer Chemother Pharmacol 2014;73:759-70.

20. Lu JF, Eppler SM, Wolf J, et al. Clinical pharmacokinetics of erlotinib in patients with solid tumors and exposuresafety relationship in patients with non-small cell lung cancer. Clin Pharmacol Ther 2006;80:136-45.

21. Peters S, Zimmermann S, Adjei AA. Oral epidermal growth factor receptor tyrosine kinase inhibitors for the treatment of non-small cell lung cancer: comparative pharmacokinetics and drug-drug interactions. Cancer Treat Rev 2014;40:917-26.

22. Brown K, Comisar C, Witjes H, et al. Population pharmacokinetics and exposure-response of osimertinib in patients with non-small cell lung cancer. Br J Clin Pharmacol 2017;83:1216-26.

23. Wu SG, Chang YL, Yu CJ, et al. Lung adenocarcinoma patients of young age have lower EGFR mutation rate and poorer efficacy of EGFR tyrosine kinase inhibitors. ERJ Open Res 2017;3. doi: 10.1183/23120541.00092-2016.

24. Chen Z, Teng X, Zhang J, et al. Molecular features of lung adenocarcinoma in young patients. Bmc Cancer 2019;19. doi:10.1186/s12885-019-5978-5.

Cite this article as: Gil HI, Um SW. The impact of age and performance status on the efficacy of osimertinib in patients with EGFR T790M-positive non-small cell lung cancer. J Thorac Dis 2020;12(3):153-155. doi: 10.21037/jtd.2019.12.80 